\title{
Relationship Between Obstructive Sleep Apnoea, Oxygen Desaturation and Cardiovascular Risk
}

\author{
LAVINIA DAVIDESCUㅍ, BEN MANSOUR MOHAMED AZZEDINE ${ }^{1 *}$, MILENA ADINA MAN²*, NICOLETA STEFANIA MOTOC², \\ IOAN ANTON ARGHIR ${ }^{3}$, RUXANDRA ULMEANU ${ }^{1}$ \\ ${ }^{1}$ University of Oradea, Faculty of Medicine and Pharmacy, 1 Universitatii Str, 410087 Oradea, Romania \\ ${ }^{2}$ Iuliu Hatieganu University of Medicine and Pharmacy, 8 Victor Babes Str, 400000 Cluj Napoca, Romania \\ ${ }^{3}$ St Andrew Clinical County Emergency Hospital, 145 Tomis Blvd, 900591 Constanta, Romania
}

\begin{abstract}
Obstructive sleep apnoea syndrome (OSAS) increases the risk cardiovascular events regardless of the presence of previous cardiovascular disease. As both OSAS and coronary heart disease (CHD) have same risk factors it's often difficult to quantify the proportion of each risk factor in developing cardiac events. The aim of this study was to evaluate the 10-year risk of developing a coronary heart disease (CHD) event or stroke in newly diagnosed OSAS patients. 65 patients diagnosed with OSAS over a period of four months in Oradea Sleep Laboratory were included. Demographic characteristics, anthropometric parameters, clinical and biochemical data, sleep disorder and daytime sleepiness assessment, results of polysomnography were collected in all patients. In 55 selected patients by age range from 34 to 74 years old, cardiovascular risk was assessed using Framingham score calculator. Statistical analysis was performed using SPSS-PC version 7.5 and Stata 10.The estimated 10-years risk of a CHD event was $18.97 \%$ ( \pm 9.67) in all cases. It was higher in men $(22.17 \% \pm 9.24)$ compare to women (12.39\% \pm 6.92) and it was not significantly different by stages of OSAS severity ( $20.58 \% \pm 9.41$ in patients with severe OSAS versus $15.4 \%$ in mild OSAS), suggesting that apnea hypopnea index is not a major confounding factor. Desaturation of oxygen is a better outcome to define the relation between OSAS and cardiovascular diseases. OSAS and cardiovascular risk factors increased risk for future adverse cardiovascular events related to the severity of oxygen desaturation.
\end{abstract}

Keywords: obstructive sleep apnoea syndrome, cardiovascular events, risk factors, oxygen desaturation

Obstructive sleep apnoea syndrome (OSAS) is a serious, potentially life-threatening condition, characterized by repetitive apneas and hypopneas during sleeping associated with multiple cardiovascular events [1]. The prevalence of moderate-to-severe OSAS among adults in general population varies between $9-14 \%$ in men and 4 $7 \%$ in women. In recent studies, it's even higher reaching $49.7 \%$ in men and $23.4 \%$ in women [2]. Predisposing factors for OSAS include older age, male gender, smoking, use of muscle relaxants, and the most important factor, obesity. In the Wisconsin Sleep Cohort Study, a 10\% weight gain was associated with a $32 \%$ increase in apnea hypopnea index (AHI) (compared to stable weight) and a six-fold increase in the risk of developing moderate to severe OSA $\left(A H I \geq 15 h^{-1}\right)$ [3].

The National Commission on Sleep Disorders Research estimated that OSAS increases the risk of heart failure by $140 \%$, the risk of stroke by $60 \%$, and the risk of coronary heart disease by $30 \%$ [4]. Several studies show the association between OSAS and cardiovascular risk factors, surrogates of cardiovascular risk, measures of cardiac and vascular structure and function in subjects without overt cardiovascular disease and important cardiovascular disease events, but none evaluated this situation in Romania [1, 3]. Traditional cardiovascular risk factors such as smoking, obesity, diabetes, blood hypertension, hyperlipidaemia, or low physical activity have been shown as independent predictors of cardiovascular disease [4]. Lung function, that is frequently impaired in OSAS, is also associated with high cardio-vascular risk [5] and a general decline in quality of life [6]. Because of common risk factors for both OSAS and cardiovascular diseases, it may be difficult to separate an independent cardiovascular risk of OSAS itself from that associated with these other comorbid factors. This study aim was to quantify the 10-year risk of developing a coronary heart disease (CHD) event or stroke in newly diagnosed OSAS patients.

\section{Experimental part}

A cross sectional study assessing obstructive sleep apnoea (OSA) was conducted in Oradea Sleep Laboratory over period of 4 for months ( $1^{\text {st }}$ of March $-30^{\text {th }}$ of J un 2016). All patients over 18 years old were screened in the Sleep Laboratory for the suspicion of Obstructive Sleep Apnea (OSA), by polysomnography (PSG). There were excluded patients with acute coronary syndrome and/or facial anatomical abnormalities and patients who refused to participate in the study. All participants gave their informed consent. Demographic and anthropometric data (age, sex, height, weight, body mass index), past medical history, smoking status, alcohol abuse, blood pressure, pulse, saturation in oxygen $\left(\mathrm{O}_{2}\right)$, biochemistry data (glycaemia, $\mathrm{Hb} 1 \mathrm{Ac}$, total cholesterol, triglycerides, $\mathrm{HDL}$ ), sleep data revealed by sleep disorder assessment, daytime sleepiness and polysomnography were all assessed in cases. The body mass index (BMI) was calculated as the weight in kilograms divided by the squared height in meters. Sleep disorders were assessed through a yes/no questionnaire specifically adapted from the Berlin Questionnaire that informs more on snoring, interruptions during sleep, apnea, morning headaches and morning fatigue. Daytime sleepiness was measured using Epworth sleepiness scale (ESS), including eight questions about chance of dozing, with possible response from 0 (never doze) to 3 (high chance of sleeping). A score greater than 10 is considered abnormal. The Questionnaireand ESS were a part of patient chart. The questionnaires were filled by a specialized nurse in sleep disorders. The outcomes of PSG consisted in apnea 
hypopnea index (AHI), oxygen desaturation index (ODI), mean oxygen saturation (satO ${ }_{2}$ mean), minimal oxygen saturation (satO $\mathrm{min})$, heart rate (HR), patient's position during sleep and sleep duration [7], defining various stages of OSA severities (from mild to severe) The device used at the Sleep Laboratory was SleepDocPORTI8, manufacturer by Dr. Fenyves und Gut Deutschland GmbH in 2010, in Germany. Systolic (SBP) and diastolic (DBP) blood pressures were taken with a standard mercury sphygmomanometer with the patient seated at rest, during the first clinical assessment. The mean of three resting values was used for evaluation of hypertension. Korotkoff phases 1 and 5 were used to record SBP and DBP respectively, using an appropriately sized adult sphygmomanometer cuff. Threshold values for hypertension were defined as $>140 \mathrm{mmHg}$ systolic and $>90 \mathrm{mmHg}$ diastolic. Patients, who had a previous diagnosis of arterial hypertension with administered antihypertensive treatment, were classified as hypertensive, irrespective of current blood pressure readings. The subjects were not stratified into different blood pressure value groups. The research was approved by the Ethics Committee of University of Oradea, Faculty of Medicine. For the assessment of cardiovascular risk (the risk of developing a coronary heart disease CHD event or stroke), over the next 10 years, among OSA patients, only those with age ranging between 34 and 74 were considered ( 55 patients) and included in a sub-study group for analysis as Framingham score calculator is defined only for this range of age. The estimation methods of cardiovascular risk were based on data adapted from the Framingham study using Age, Sex, Hypertension, Hypertension treatment Yes/No, Smoking, Diabetes, Body Mass Index (BMI). So, all available data including age, gender, blood pressure, antihypertensive treatment, BMI, smoking habit, presence of diabetes mellitus were determined and exsmokers were regarded as nonsmokers in this model. Statistical analysis was performed using SPSS-PC version 7.5 and Stata 10. Data were expressed as mean, standard deviations, ranges, depending on the situation. T-test was used for group comparisons (smokers and non-smokers). Pearson test was used to assess possible correlations between different parameters. $P$ value $<0.05$ was considered statistically significant.

\section{Results and discussions}

65 patients over 18 years old, with mild to severe OSA were included, 41 males (63.07\%) and 24 females (36.93\%), mean aged $52.24 \pm 13.66$ years (Table 1 ). The mean value of BMI was $36.30 \pm 7.47 \mathrm{~kg} / \mathrm{m}^{2}$. Although there was no statistically significant difference in BMI values distribution by gender, men had greater values of weight and height.

Out of 65 patients, 46 ( $70.76 \%$ ) had severe OSA (AHI>30 events/hours of sleep), mostly males (69.57\%) and $36.96 \%$ of them older than 50 years old. In the group with mild OSAS $(n=10)$, the average BMI was $33.46 \mathrm{~kg} / \mathrm{m}^{2}( \pm 4.24)$, average SBP was $127.78 \mathrm{mmHg}( \pm 13.94)$. Two patients were diabetics, one smoker and three had cardiovascular disease history. In the group with moderate OSA $(n=9)$, the average BMI was $30.55 \mathrm{~kg} / \mathrm{m}^{2}( \pm 3.03)$; average SBP was $123.75 \mathrm{mmHg}( \pm 42.43)$. In the group with severe OSAS $(n=46)$, with AHI $>30$, the average of $B M I$ was high $\left(38.28 \mathrm{kh} / \mathrm{m}^{2} \pm 7.86\right)$, suggestive for obesity, and the average of SBP was $140.13 \mathrm{mmHg}( \pm 55.26)$ suggestive for hypertension. Eight patients had diabetes, eightwere active smokers and eleven had cardiovascular disease history (Table 1). Regarding sleep parameters, there were noticed significant increased values of Epw orth Sleepiness scale (ESS) associated with severe OSAS $(9.93 \pm 6.13$ points in patients with AHI>30) compare to moderate OSAS ( 6.78 \pm 4.64 ) (Table 1). In mild OSAS cases, the average AHI was low $(10.35 \pm 3.47)$, sat02min $=70.30 \%( \pm 17.47)$ and satO mean $=95.10 \%( \pm 1.97)$ compare to severe OSAS, with increased values of AHI $(56.89 \pm 20.03)$ by hour of sleep, and sat0 mean $(88.39 \% \pm 20.92)$ (Table 1).

$70.76 \%$ of patients had arterial hypertension based on either a prior history or blood pressure recording in Sleep Laboratory. Only $46.15 \%$ patients had received antihypertensive treatment in their past medical history. In patients without positive history of arterial hypertension or any other treatment, both systolic and diastolic hypertension (SBP >140mmHg and DBP >90 $\mathrm{mmHg}$ ) were identified in $12.31 \%$, while $7.69 \%$ had isolated systolic hypertension (SBP $>140$, DBP $<90 \mathrm{mmHg}$ ) and $4.61 \%$ had only diastolic hypertension (SBP $<140$, DBP $>90$ $\mathrm{mmHg})$. The frequency of diabetes was $20 \%(n=13$; seven men and six women). $15.38 \%$ of patients were current smokers, although a further of $29.23 \%$ had recognized exposure to smoking in their past.

Distribution of hypertension and OSAS was assessed prior to nasal continuous positive airway pressure and there were no significant differences between smokers, exsmokers and nonsmokers concerning the severity of $\mathrm{AHI}$, although SBP levels were higher among current smokers $(140,95 \% \mathrm{Cl}: 125.06-154.93 \mathrm{mmHg})$, than either exsmokers, (130.94, 95\% Cl: 123.88-144.01 mmHg) or nonsmokers (136.11, 95\% Cl: $129.04-143.17 \mathrm{mmHg}$ ), $\mathrm{p}<0.05$ by analysis of variance (Table 2 ).

The estimated 10-years risk of a CHD event was 18.97\% ( \pm 9.67 ) in 55 participants (37 males and 18 females) stratified in 3 equal subgroups according to $\mathrm{AHI}$ levels and OSA severity (Table 3). Males had a higher predicted CHD event risk (22.17\% \pm 9.24$)$ than females $(12.39 \% \pm 6.92)$. $\mathrm{CV}$ risk seems to be less influenced by the severity of OSAS $(23.07+/-8.79$ corresponding to increased $\mathrm{AHI}=72.15)$ (Table 3). The mean value of the lowest oxygen desaturations was $66.16+/-13.17$.

The 10 years estimation of $\mathrm{CHD}$ event risk was greater among severe OSAS cases $(20.58 \% \pm 9.41)$ versus mild forms $(15.4 \%)$, mostly related with severe oxygen desaturation $(63.30+/-16.72$ versus $70.30+/-17.47$; $p=0.014)$. A high prevalence of arterial hypertension (70.76\%) and noninsulin dependent (type II) diabetes mellitus were recorded ( $20 \%$ ) and thus the authors cannot sustain that the predicted cardiovascular risk calculated in this study is entirely separate from OSA related risk. Nonetheless, the small difference in predicted risk, when all cases were stratified according to OSA severity, suggests that it was nota major confounding factor in these calculations and even the patients with mild OSAs have an estimated high risk of cardiovascular events in the following 10 years.

This is one of the first surveys of OSAS among Romanian Sleep Laboratory patients to examine a prospective risk of cardiovascular disease related to coexisting factors other than OSAS. Results indicated that OSA patients are at a higher risk of future cardiovascular events, especially for CHD. The incidence and prevalence of OSA has increased dramatically in last decades, all over the world, with impact on decreasing the quality of life and work [8]. The high risk of cardiovascular diseases related OSA was reported in many studies $[9,10]$. Stanford Group reported several decades ago, in 1990, a high prevalence of cardiovascular disease (systemic hypertension, coronary artery disease and cerebrovascular disease) in recently diagnosed OSA. 
Table 1

PARTICIPANTS CHARACTERISTICS BY OBSTRUCTIVE SLEEP APNOEA SEVERITY

\begin{tabular}{|c|c|c|c|c|c|}
\hline & Cases $(n=65)$ & $\begin{array}{l}\text { AHI [5-14.9] } \\
\text { Mild OSA (n=10) }\end{array}$ & $\begin{array}{lr}\text { AHI } & {[15-30]} \\
\text { Moderate } & \text { OSA } \\
(\mathbf{n}=9) & \end{array}$ & $\begin{array}{l}\text { AHI }>30 \\
\text { Severe OSA } \\
(n=46)\end{array}$ & $\mathbf{P}$ \\
\hline Mean age & $53.18+/-13.66$ & $42.30+/-15.05$ & $53.67+1-9.64$ & $55.46+/-13.11$ & \\
\hline Males $(N ; \%)$ & $41(63 \%)$ & $5(50 \%)$ & $4(44.44 \%)$ & $32(69.57 \%)$ & \\
\hline Females $(\mathrm{N} ; \%)$ & $24(37 \%)$ & $5(50 \%)$ & $5(55.56 \%)$ & $14(30.43 \%)$ & \\
\hline Males $>50$ yrs $\left(N_{;} \%\right)$ & $25(60.98 \%)$ & $3(30 \%)$ & $4(44.44 \%)$ & $17.00(36.96)$ & \\
\hline $\begin{array}{l}\text { Females }>60 \text { yrs } \\
(\mathrm{N} ; \%)\end{array}$ & $9(37.50 \%)$ & $1(10 \%)$ & $2(22.22 \%)$ & $6.00(13.04)$ & \\
\hline $\begin{array}{l}\text { Mean Body Mass } \\
\text { Index (BMI) kg/m }\end{array}$ & $36.47+/-7.47$ & $33.46+/-4.24$ & $30.55+/-3.03$ & $38.28+/-7.86$ & 0.436 \\
\hline $\begin{array}{l}\text { Mean Systolic Blood } \\
\text { Pressure (SBP) }\end{array}$ & $135.80+/-21.61$ & $127.78+/-13.94$ & $123.75+/-42.43$ & $140.13+/-55.26$ & 0.069 \\
\hline $\begin{array}{l}\text { Mean Diastolic Blood } \\
\text { Pressure (DBP) }\end{array}$ & $84.55+/-9.01$ & $81.67(3.54)$ & $80.63(27.61)$ & $86.03(32.55)$ & 0.176 \\
\hline $\begin{array}{l}\text { Diabetes } \\
(\mathrm{DM})(\mathrm{N} ; \%)\end{array}$ & $13(20 \%)$ & $2(20 \%)$ & $3(33.33 \%)$ & $8(17.39 \%)$ & 0.187 \\
\hline $\begin{array}{l}\text { Active Smokers }(\mathbb{N} ; \\
\%)\end{array}$ & $10(15.38 \%)$ & $1(10 \%)$ & $1(11.11 \%)$ & $8(17.39 \%)$ & 0.861 \\
\hline $\begin{array}{l}\text { Mean score of } \\
\text { Epworth Sleepiness } \\
\text { scale (ESS) points }\end{array}$ & $9.08+/-5.57$ & $6.78+/-4.64$ & $7.22+/ .4 .38$ & $9.93+/-6.13$ & 0.169 \\
\hline $\begin{array}{l}\text { Mean saturation of } \\
\text { oxygen }(\%)\end{array}$ & $90.03+/-9.24$ & $95.10+/-1.97$ & $92.44+1-3.00$ & $88.39+1-20.92$ & 0.079 \\
\hline \begin{tabular}{l:|l} 
Apnea Hypopnea & \\
Index (AHI) & \\
events/hour &
\end{tabular} & $44.56+/-25.82$ & $10.35+/-3.47$ & $19.56+/-5.00$ & $56.89+/-20.03$ & \\
\hline $\begin{array}{l}\text { Dyslipidemia } \\
(\mathrm{N} ; \%)\end{array}$ & $10(15.38 \%)$ & $2(20 \%)$ & $1(11.11 \%)$ & $7(15.22 \%)$ & \\
\hline $\begin{array}{l}\text { Cardiovascular } \\
\text { disease history (N; \%) }\end{array}$ & $15(23 \%)$ & $3(30 \%)$ & $1(11.11 \%)$ & $11(23.91 \%)$ & \\
\hline \multicolumn{6}{|c|}{$\begin{array}{l}\text { Categorical variables displayed as percentages, contimuous variables presented as mean } \pm \text { standard deviation. } \\
P \text { values represent the results of ANOVA analysis of variance (contimuous) for differences of means among groups divided } \\
\text { by the severity of Obstructive Sleep Apnea. }\end{array}$} \\
\hline
\end{tabular}

Table 2

DISTRIBUTION OF HYPERTENSION AND OSAS SEVERITY BY SMOKING STATUS OF PATIENTS

\begin{tabular}{|l|l|l|l|l|}
\hline & Total cases (\%) & SBP & DBP & AHI (events/hour) \\
\hline Smokers (\%) & $10(15.38 \%)$ & 140.00 & 89.00 & 42.80 \\
\hline Ex-smokers (\%) & $19(29.23 \%)$ & 133.95 & 82.37 & 45.82 \\
\hline Nonsmokers (\%) & $36(55.38 \%)$ & 136.11 & 84.44 & 44.39 \\
\hline
\end{tabular}

Legend: OSAS= obstructive sleep apnea syndrome; $\mathrm{SBP}=$ Systolic Blood Pressure; $\mathrm{DBP}=$ Diastolic

Blood Pressure, AHI= Apnea Hypopnea Index;

The major health risk is represented by the strong association between OSA and acute cardiovascular events (like myocardial infarction, stroke or nocturnal sudden death) as well as chronic conditions (like systemic hypertension, coronary artery disease and heart failure) [10]. The association between OSA and cardiovascular mortality is complicated because of supplementary risk factors (obesity, insulin resistance, and dyslipidaemia) but OSAS remains an independent risk factor for atherosclerotic heart disease [11]. OSAS can increase the risk of developing cardiovascular disease through a number 
Table 3

TEN YEAR PREDICTED CORONARY HEART DISEASE (CHD) EVENT RISK STRATIFIED ACCORDING TO APNEA- HYPOPNEA INDEX (AHI)

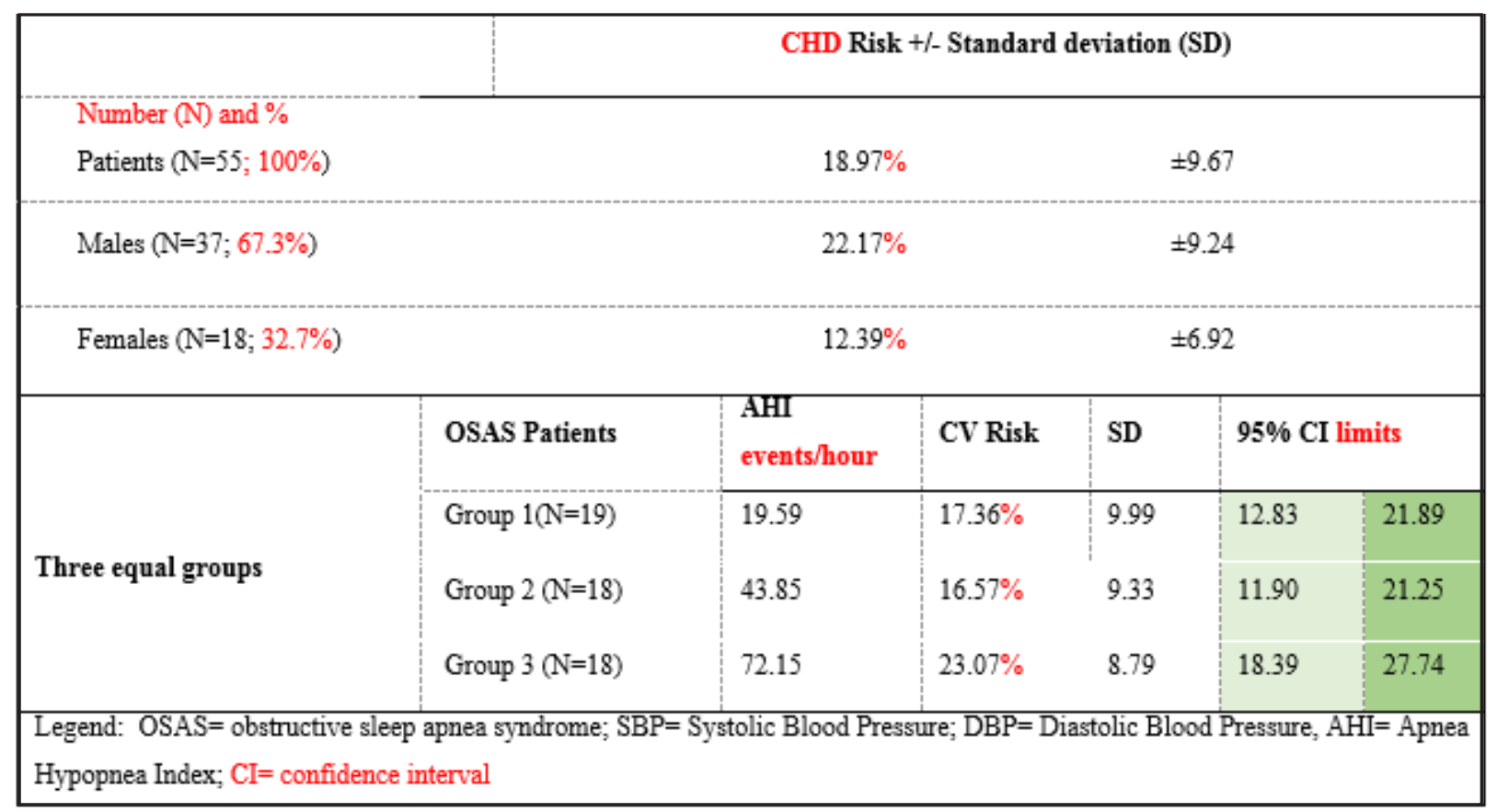

of mechanisms (intermittenthypoxia, sleep fragmentation, chronic sympathetic activation, and systemic inflammation) [12,13]. OSA associates with both coronary and cerebrovascular morbidity and mortality suggests the possibility of including sleep disturbances in the top 10 potentially modifiable cardiovascular risk factors. Kendzerska et al. reported that AHI can predict cardiovascular events by univariate analysis, but without significance in a multivariable model adjusted for potential confounders [12]. We didn't find any significant risk factor for severity of OSA, because we did not evaluate independent predictor for cardiovascular disease in multivariate analyse. This risk assessment did not take into account any possible additional independent risk of cardiovascular disease related to the patients' OSA, although it is interesting to note that when the data were stratified according to OSA severity, increasing AHI levels were not associated with higher predicted risk from these other comorbid factors. The predicted prospective risk of CVD in the study group was estimated according to models based on the Framingham Study. The mean value of $18.9 \%$ for estimated 10-yr risk of CVD events is likely to be conservative, since we didn't have data concerning LDL and HDL levels (the risk was calculated using BMI). The risk related to obesity may be higher in OSA since these patients have a higher propensity to central obesity which appears to be associated with higher cardiovascular morbidity and mortality independent of BMI. The prevalence of diabetes mellitus in $20 \%$ of the patients may simply reflect the degree of obesity present in the study population, but the metabolic effects of increased sympathetic tone and elevated circulating catecholamines due to OSAS, may also contribute to the development of diabetes mellitus. The model also does not take into account factors related to OSA itself that might contribute to CVD such as recurrent nocturnal hypoxia and increased sympathetic drive. As over $23 \%$ of the study population al ready had a diagnosis of significant overt cardiac disease (ischemic heart disease, cardiac failure or arrhythmia) prior to the diagnosis of OSA, their 10-yr risk of a new CVD is probably underestimated by these prediction models. The great majority of patients had relatively severe OSA/
(70.76\%) and were significantly obese as a whole because they were diagnosed with OSA at late stage $(70.8 \%$ had $\mathrm{AHI}>30$ events by hour of sleep). Sanches de la Torre et al. reported in 2013, a 10-year risk for coronary heart disease (CHD) of $13.9 \pm 0.9 \%$ in males, $12.3 \pm 1.4 \%$ for stroke; with a combined 10 year risk for stroke and CHD events of $32.9 \pm 2.7 \%$ [14]. Divided OSAS patients into groups according to FRS score determined the identification of a low-risk group (with FRS < 10) and non-low-risk group (with FRS $\geq 10$ ) [11]. Recent studies demonstrate that OSA is a common treatable cause of drug-resistant hypertension, risk factor for paroxysmal supraventricular tachycardia and atrial fibrillation, is an independent risk factor for ischemic stroke $[15,16]$. OSAS comorbidities are not fully identified, butcardiovascular diseases (treatmentresistanthypertension, arrhythmias, myocardial infarction, even sudden death), metabolic diseases (obesity and diabetes), obstructive lung diseases (COPD and asthma), neurological diseases, psychiatric disorders are considered pathological consequences, that can be prevented [17$20]$ in order to preserve the social integration and professional activity [8]. The education of patients to recognize the symptoms of sleep apnea and to apply the available effective treatments is a stringent necessity $[17,18]$. The limitation of the presentstudy was the absence of a control population, but this was not regarded as important since the study did not seek to identify any separate cardiovascular risk related to OSAS. The above limitations need to be taken into account in the interpretation of the present data, but nonetheless should not detract from the core conclusion of the study, which is that OSA patients are already at high risk of cardiovascular disease from other comorbid disease-; and studies, which are seeking to identify an independent cardiovascular risk from OSAS, must take other variables into account in their assessment. The data demonstrate the predicted risk of cardiovascular disease is high and should provide useful baseline data to compare with other studies that evaluate cardiovascular morbidity in populations of OSA patients, particularly where an adequate control group is not included. By demonstrating a relatively high prevalence of other comorbid disease, these findings provide potentially 
useful data to help identify other factors that would need to be included in a matched control population for prospective controlled studies that seek to establish an independent cardiovascular risk related to OSA itself. Improvement of early diagnosis and therapeutic control of OSA is also required for influencing cardiovascular diseases [19] or other risk factors [20] and co-morbidities [18, 2124].

\section{Conclusions}

A high prevalence of coexisting OSA and cardiovascular risk factors within a Romanian Sleep Laboratory population was determined. An increased risk for future adverse cardiovascular events is influenced by the oxygen desaturation than by elevated apnea hypopnea index, suggestive for the severity of obstructive sleep apnoea syndrome. Since it is known conservative treatment and nasal continuous positive airway pressure treatment will reduce the risk of cardiovascular morbidity and mortality, clinicians should be aware of the high prevalence of these comorbidities of OSA and should adopta multidisciplinary approach in these high-risk groups of population. Although sleep apnoea is not yet integrated as a variable into formal risk assessment algorithms, there is increasing awareness within the cardiovascular community of its importance in the causation or promotion of hypertension, coronary artery disease, heart failure, atrial arrhythmias, and stroke, and thus, not surprisingly, as a predictor of premature cardiovascular death.

\section{References}

1.JEAN-LOUIS, G., ZIZI, F., CLARK, L.T., BROWN, C.D., MCFARLANE, S.I., J. Clin. Sleep. Med., 4, nr. 3, 2008, p. 261.

2.KOO, D.L., NAM, H., THOMAS, R.J., YUN, C.H., J. Stroke., 20, nr.1, 2018, p.12.

3.MAEDER, M.T., SCHOCH, O.D., RICKLI, H., Vasc. Health. Risk. Manag., 12, 2018, p. 85.

4.LUYSTER, F.S., KIP, K.E., BUYSSE, D.J ., AIYER, A.N., REIS, S.E., STROLLO, P., J. Sleep. 37, nr. 3, 2014, p.593.

5.SILVESTRE, O.M., NADRUZ, W., ROCA, G.Q., CLAGGETT, B., SOLOMON, S.D., MIRABELLI, M.C., LONDON, S.J ., LOEHR, L.R., SHAH, A.M., J. Am. Coll. Cardiol., 72, nr 10, 2018, p. 1109.

6.OTELEA, M.R., ARGHIR, O.C, ZUGRAVU, C., NAGHI, E., ANTONIU, S., RASCU, A., Rev. Chim. (Bucharest), 69, no. 2, 2018, p. 346.
7.DAVIDESCU, L., MANOLESCU, D., ULMEANU, R., OANCEA, C., Noninvasive Ventilation in Neuromuscular Diseases in Noninvasive Ventilation in Medicine - Recent Updates, It Edition, IntechOpen, Mayank Vats (editor), London, 2019, p.111.

8.RASCU, A., ARGHIR, O.C., OTELEA M. Rom J Legal Med, 24, nr. 2, 2016, p.118.

9.WANG, L., CAl, A., ZHANG, J., ZHONG, Q., WANG, R., CHEN, J., ZHOU, Y., Medicine (Baltimore). 95, nr. 39, 2016, p.e4691.

10.MCNICHOLAS, W.T., BONSIGNORE, M.R., Eur Respir J, 29, nr. 1, 2007, p. 156.

11.GRANDNER, M.A., ALFONSO-MILLER, P., FERNANDEZ-MENDOZA, J., SHETTY, S., SHENOY, S., COMBS, D., Curr Opin Cardiol. 31, nr. 5, 2016, p.551.

12.KENDZERSKA, T., GERSHON, A.S., HAWKER, G., LEUNG, R.S., TOMLINSON, G. PloS. Med., 11, nr. 2, 2014, p. e1001599.

13.DRAGER, L.F., MCEVOY, R.D., BARBE, F., LORENZI-FILHO, G., REDLINE, S., INCOSACT Initiative (International Collaboration of Sleep Apnea Cardiovascular Trialists), Circulation, 136, nr. 19, 2017, p.1840. 14.SANCHEZ-DE-LA-TORRE, M., CAMPOS-RODRIGUEZ, F., BARBE, F. Lancet. Respir. Med., 1, nr.1, 2013, p. 61.

15.WANG, X.F., LI, Q.Y., WAN, H.Y., LI, M. Zhonghua. Yi. Xue. Za. Zhi., 87, nr. 31, 2007, p.2176.

16.RIVAS, M., RATRA, A., NUGENT, K. Anatol. J. Cardiol., 15, nr. 11, 2016, p.944.

17.TRENCHEA, M, RASCU, A, SUTA, M, ARGHIR OC. Pneumologia, 66, nr. 3, 2017, p. 140.

18.OTELEA, M.R., TRENCHEA, M., ARGHIR, O.C., VELESCU, L., DANTES,

E., BECHIR, E.S., ELSAAFIN, M., RASCU, A. Rev. Chim. (Bucharest)., 69, no. 1, 2018, p.282.

19.BECHIR, E.S., BECHIR, A., ARGHIR, O.C., CIAVOI, G., GIOGA, C., MOLA, F.C., DASCALU, I.T., Mat. Plast., 54, nr. 2, 2017, p. 304.

20.TRENCHEA, M., RASCU, A., ARGHIR, O.C. Rom J Occup Med. 69(1), 2018, p.6.

21.JIMBOREAN, G., SZASZ, S., SZATHMARY, M., CSIPOR, A., ARGHIR, O.C, NEMES, R.M, POSTOLACHE, P., IANOSI, E.S. Rev. Chim. (Bucharest), 69, no. 4, 2018, p. 1014.

22.ANTON, A., TOFOLEAN, D.E. Sleep Med.40(1), 2017, p.E16.

23.JIMBOREAN, G., ARGHIR, O.C., CAMBREA, S.C., DANTES, E., SOCACI, A., OTELEA, M.R., BECHIR, E.S., IANOSI, E.S. Rev. Chim. (Bucharest), 69, no.8, 2018, p. 2050.

24.TRENCHEA, M., DANTES, E., VELESCU, L., DELEANU, O., SUTA, M., ARGHIR, 0. CHEST, 148 (4_MeetingAbstracts), 2015, p. 1068A; doi:10.1378/chest.2270484

Manuscript received: 14.05 .2019 